\title{
FRIDA KAHLO: ENTRE PINTURAS E ESCRITOS1
}

Brígida Duarte de Oliveira Medeiros

\section{Introdução}

Frida Kahlo (1907-1954) começou a pintar seu imaginário em meio à Revolução Mexicana, iniciada em 1910, que conseguiu derrubar a ditadura de trinta e quatro anos de Porfirio Díaz. Valorizar as raízes mexicanas para despertar um maior sentimento de patriotismo na população era o grande interesse do novo governo. Graças a esse anseio, surge o Muralismo Mexicano, movimento artístico com forte preocupação social que exaltava, a partir de escalas monumentais, a imagem do povo mexicano, sua vida, história e valores. Em meio a isso, Frida apresenta-se como disparate: além de ser uma mulher em contexto majoritariamente masculino, a artista desenvolveu uma temática ligada mais diretamente ao âmbito pessoal do que ao social e político. A pintora acaba então por criar uma obra voltada para si que ainda hoje permite novas leituras em associação a diferentes campos do conhecimento, diferentemente das datadas composições do Muralismo.

Este artigo apresenta, de forma modificada, o pré-projeto de pesquisa submetido para seleção de candidatos para o Mestrado Acadêmico em Arte na linha de pesquisa 'Teoria e História da Arte' do Programa de Pós-graduação em Arte do Departamento de Artes Visuais da Universidade de Brasilia. 
orgulho de Frida Kahlo por suas raízes mexicanas foi explorado por meio da mexicanidad, valorização da identidade nacional, na produção de autorretratos e em sua difundida imagem com trajes e penteados tipicamente locais. Bebendo da fonte da arte popular de seu país, e apesar de não explorar temáticas religiosas, artista incorporou, em alguns de seus quadros, características formais e estilísticas dos ex-votos, prática cultural de cunho religioso muito propagada no México, na qual as pinturas geralmente seguem uma mesma estrutura composicional, como o uso de legendas. $A$ inserção de legendas em seus quadros é o fator desencadeador desta pesquisa que busca fomentar questões sobre a visualidade e textualidade na produção de Frida Kahlo. Enquanto nos ex-votos as legendas servem para informar $\circ$ nome do agraciado, o milagre e a santidade que $\circ$ realizou, nas imagens feitas pela pintora tinham diferentes finalidades. Majoritariamente os escritos eram utilizados para identificar o retratado, o local e a data da fruição da obra, por vezes também vinham como dedicatória para aqueles a quem as pinturas seriam ofertadas.

Outras vezes, a escrita ocorria como uma frase significativa para o composição na qual estava inclusa. A produção escrita da mexicana, porém, vem antes de sua consolidação como artista: Frida foi uma fértil redatora de cartas desde sua adolescência e até o fim de sua vida. Nos completos relatos que enviava para seus amigos, estavam, principalmente, atualizações de seu estado de saúde e comentários sobre as obras nas quais estava trabalhando no momento. Destaca-se nesse material a inserção de palavras em língua inglesa e a presença de neologismos criados pela pintora, como buten (muito(s), muita(s), possivelmente derivado do alemão). A inclusão de desenhos, sobrepostos ou acompanhando as palavras, mais uma vez evidencia a união de aspectos visuais e verbais.

A atitude franca e sem reservas empregada nas cartas também está presente no diário íntimo ao qual a artista se dedicou entre os anos de 1944 e 1954, sua última década de vida. Composto por relatos, cartas, poemas, aquarelas e desenhos que foram gravados em diversas cores, o material é definido por Carlos Fuentes como diário pintado. A letra de Frida, que se apresenta a princípio firme, vai se tornando cada vez mais incerta e trêmula à medida que sua saúde vai se deteriorando ao decorrer dos anos. O mesmo acontece com o apuro e acabamento dos desenhos presentes no diário.

Os poemas escritos por Frida Kahlo são majoritariamente formados por associações de palavras ou por versos curtos. Segundo estudiosos sobre sua vida e obra, sua poesia pode ser entendida como parte do Estridentismo, movimento artístico mexicano iniciado em 1921 que tinha como principais preceitos " $a$ emoção como fonte da criação estética, os protestos radicais, a força interior, a associação livre, 
pirotecnias verbais [...]" (BASTOS, 2010: 73-4). Aqui é proposto tratar da textualidade em meio à visualidade na obra autorreferencial da pintora mexicana Frida Kahlo. Considerando seu contexto social e artístico, sua posição enquanto mulher artista e os diferentes formatos nos quais desenvolveu sua produção visual, verbo-visual e verbal.

Justificativa

Entre os anos de 1920-50, Frida Kahlo desenvolveu uma produção pictórica diretamente voltada para a temática pessoal. É notável o crescente interesse, em escala mundial, por sua vida e obra, que por vezes acaba sendo encarada como uma mera ilustração de sua biografia. Entretanto, pouco foi pesquisado sobre sua produção para além das pinturas.

Sua produção verbal e verbo-visual se concentra, principalmente, nas cartas que a artista escreveu para seus amigos e em seu diário íntimo, que une poemas, relatos e desenhos registrados nos últimos dez anos de sua vida. Esse material, além de seu valor documental, estabelece um diálogo entre as dimensões estética e poética.

A relevância desta pesquisa se destaca pelo ensejado acréscimo ao tema de onde se deriva. A investigação sobre os elementos linguísticos em meio a visualidade presente na produção de Frida Kahlo abre espaço para a inclusão da obra da pintora no espaço ocupado por outros artistas que, de alguma forma, também uniram visualidade e textualidade, como Van Gogh, Delacroix, Duchamp, e tantos outros.

A pesquisa se desenvolverá partindo da análise de um recorte definido: as pinturas produzidas entre as décadas de 1920-50, o diário feito entre 1944 e 1954 e as cartas escritas durante toda a vida, articulando-se com a bibliografia selecionada sobre a obra de Frida Kahlo, suas especificidades artísticas, além dos escritos sobre arte e vida, arte e literatura, autobiografia, autoficção, livros-diários de artista, pintura ex-votiva, etc.

\section{$\underline{\text { Objetivo Geral e Específicos }}$}

O objetivo desta pesquisa é estabelecer uma reflexão teórica sobre a relação entre arte e literatura a partir da obra da pintora mexicana Frida Kahlo de modo a articular os conceitos presentes na bibliografia específica da temática escolhida. 
Também interessa desenvolver uma investigação das produções visuais, verbais e verbo-visuais da artista, como suas pinturas, suas cartas e seu diário íntimo. Seguem os objetivos específicos: a) Investigar as obras de Frida Kahlo que trazem consigo a relação entre visualidade e textualidade; b) Buscar obras de artistas que também se localizam no eixo temático da pesquisa para relacioná-las com a produção da artista mexicana; c) Aprofundar as noções e conceitos da esfera da teoria, aliando-os aos conhecimentos oriundos de outros campos, como a literatura; d) Fomentar pesquisa teórica a fim de ampliar as considerações e debates na área das artes visuais;

\section{Revisão de Literatura}

A argumentação sobre a relação entre texto e imagem na obra de Frida Kahlo parte da temática pessoal que a artista imprimiu, direta ou indiretamente, em tudo que produziu. Para tornar viável a investigação dos fatores estéticos, conceituais e poéticos da produção da artista, sua biografia será utilizada como um apoio, um dos materiais para entendê-la.

O livro de Hayden Herrera, Frida: a biografia (2012) é um dos mais disseminados e aceitos textos sobre a pintora, onde a historiadora da arte desenvolve completos relatos sobre sua história de vida, incluindo diversas correspondências escritas por Frida, entrevistas com pessoas que foram próximas à ela, a contextualização do cenário social, político e artístico em que viveu, e extensas descrições sobre momentos que impulsionaram a fruição de suas obras. É preciso ressaltar que apesar da grande maioria das pinturas serem autorretratos, também pintou diversas naturezas mortas e retratos de pessoas de seu convívio:

"e, nas raras ocasiões em que trabalha sob encomenda, ela não necessariamente pintava o que o cliente esperava, [...] Frida não conseguia evitar a tendência de transformar a pintura em uma declaração pessoal intimamente relacionada a eventos de sua própria vida." (HERRERA, 2012: $351)$.

Herrera traz uma grande parcela das obras de Frida Kahlo ilustrada e comentada, incluindo aquelas em que a artista inseriu legendas, recurso muito utilizado nas pinturas ex-votivas tão presentes no imaginário mexicano. Legendas estas que ela utilizava para identificar a pessoa retratada, por vezes ainda citava sua idade, expunha o local e data de quando foram realizados e incluía uma dedicatória para aqueles a quem as composições seriam ofertadas. Essa inclusão de elementos linguísticos na 
visualidade está presente no quadro Frida e Diego Rivera (1931) em uma fita carregada por um pássaro.

[...] uma espécie de retrato de casamento pintado um ano e meio depois do matrimônio. [...] a tela tem uma inscrição informativa escrita em uma fita, recurso usado por Kahlo e Rivera que deriva da pintura colonial mexicana. A mensagem é de tom ingênuo, e a tela é vazada em estilo naïf e folclórico: 'Aqui você vê a mim, Frida Kahlo, com meu amado marido Diego Rivera. Pintei esse retrato na bela cidade de São Francisco para nosso amigo sr. Albert Bender, no mês de abril do ano de 1931. (HERRERA, 2012: 156).

Em sua tese intitulada Da imagem à palavra: medo e ousadia em Hye Seok Rha, Tarsila do Amaral e Frida Kahlo, a pesquisadora em Literatura Comparada So Ra Lim investiga a produção das mulheres artistas, voltando o olhar para como elas desenvolvem a autorrepresentação e suas narrativas de cunho pessoal, dando destaque à obra das três indicadas no título. A autora disserta sobre a relação entre arte e literatura desde a antiguidade clássica e traça uma cronologia sobre a inserção da mulher em ambos os campos. É evidenciado durante o texto que mesmo depois de toda a transformação social, a herança da produção feminina ainda é, por vezes, vista como inferior, principalmente porque, em grande parte dos casos, desenvolve uma temática pessoal com caráter confessional. Lim se posiciona afirmando que "[...] articular para si própria a sua experiência de mulher significa manifestar seu desejo, consolidar sua identidade e legitimar sua existência [...]" (LIM, 2005: 32).

Uma análise verticalizada dos elementos estéticos e poéticos das composições de Frida Kahlo é desenvolvida pela pesquisadora. Destaca-se a investigação feita sobre um trecho, de quatro páginas e um desenho, do diário da pintora mexicana no qual ela relata sobre a amiga imaginária que teve na infância, intitulado Origen de Las Dos Fridas = Recuerdoz. Sobre a manipulação e interação entre elementos verbais dentro da composição plástica, Lim comenta:

O desenho é verticalmente dividido na mesma proporção em três partes. No lado esquerdo da composição, aparece uma moldura com o título, escrito em maiúscula: "LAS DOS FRIDAS". É curioso observar que Frida quebra a palavra "FRIDAS" em duas partes - "FRI-DAS" —, o que, de certa forma, visualiza tipograficamente a existência de dois eus, inclusive o texto em si é escrito também duas vezes: na primeira versão, em tinta azul, e na segunda, em 
tinta marrom, sobreposto ao original, [...] O próprio texto é duplicado como se fosse narrado em duas vozes. (LIM, 2005: 279)

O mais rico e completo objeto de estudo da produção escrita de Frida Kahlo é seu diário íntimo, registrado entre os anos de 1944 e 1954. Diferente de outros livros de artista que funcionam exclusivamente como registo do processo de fruição de sua obra, o diário de Frida Kahlo ganha reconhecimento como obra de arte com uma produção com estilo diferenciado daquele explorado em seus quadros. Cartas, anotações e lembranças escritas, muito próximas à linguagem poética, se relacionam com aquarelas e desenhos que não possuem, e nem tem a pretensão de possuir, o apuro técnico e o cuidado com os detalhes como os empregados nas pinturas.

Repleto de rasuras, manchas e sobreposições, quase como um palimpsesto, se compôs o diário íntimo da artista. Publicado décadas após sua morte, hoje com o título de $O$ diário de Frida Kahlo - Um autorretrato íntimo, acompanha tradução em diferentes línguas.

$\mathrm{Na}$ edição com tradução para o português por Mário Pontes, o texto introdutório escrito por Frederico Morais traz uma reflexão onde a relação entre arte e literatura também pode ser entendida:

Para Frida Kahlo, o conceito de autorretrato abrange tudo o que se encontra ao seu redor, ou mesmo distante, no tempo e no espaço, tudo o que ela viveu, pensou, sentiu. [...] Tudo que foi tocado por ela - objetos, a flora e a fauna, corpos, roupas, países - e mesmo o imaterial do mundo: ideias, ideologias, crenças - tudo é parte de sua biografia, [...] Tudo é biografia. Tudo é pintura. (MORAIS in KAHLO, 2012:18).

Por abranger os principais conceitos deste projeto, escritos como Frida Kahlo: A biografia de Hayden Herrera; Da imagem à palavra: medo e ousadia em Hye Seok Rha, Tarsila do Amaral e Frida Kahlo escrito por So Ra Lim; e, a publicação do diário da pintora mexicana intitulada $O$ diário de Frida Kahlo - Um autorretrato íntimo são elementos fundamentais para o desenvolvimento da pesquisa pretendida. A metodologia adotada se caracteriza como exploratória, partindo do levantamento bibliográfico adequado ao aprofundamento dos conceitos abordados em suas diferentes áreas de conhecimento, simultaneamente com o levantamento imagético e a pesquisa documental. $O$ processo de investigação contará com análise do material imagético (pinturas e desenhos) e documental (diário e cartas) resultando de observação sistemática e respaldado pela bibliografia selecionada. Os registros 
METAgraphias: letra E (sobre errância e-Rancièrráticas) v.2 n.2 junho| 2017 Frida Kahlo: entre pinturas e escritos • Brígida Duarte (brigidaduart@hotmail.com)

da pesquisa de campo na Cidade do México, com visitas à Casa Azul e diferentes museus e pontos culturais mexicanos, também auxiliarão no desenvolvimento da pesquisa.

$\underline{\text { Referência Bibliográfica }}$

ABREU, Simone Rocha de. A produção artística como fábula: um estudo de algumas obras de Frida Kahlo. Dissertação apresentada ao IV Encontro de História da Arte - Unicamp, 2008.

BASTOS, Marli Miranda. Frida Kahlo: Para além da pintura. Rio de Janeiro: Mauad X, 2010.

DUARTE, Ana Helena da Silva Delfino. O imaginário ex-votivo na pintura de Frida Kahlo. São Paulo: Revista Cordis ${ }^{\circ} 12$, 2014.

FIGUEIREDO, Eurídice. Mulheres ao espelho: autobiografia, ficção e autoficção. Rio de Janeiro: EdUERJ, 2013.

HAGHENBECK, Francisco Geraldo. O segredo de Frida Kahlo. São Paulo: Editora Planeta do Brasil, 2011.

HERRERA, Hayden. Frida: a biografia. São Paulo: Globo, 2011.

KAHLO, Frida. Cartas apaixonadas de Frida Kahlo. [Compilação de Martha Zamora; tradução de Vera Ribeiro]. Rio de Janeiro: José Olympio, 2011.

KAHLO, Frida. O diário de Frida Kahlo: um autorretrato íntimo. [Tradução de Mário Pontes; introdução de Federico Morais]. Rio de Janeiro: José Olympio, 2012.

KETTENMANN, Andrea. Kahlo. Lisboa: Taschen, 2006.

LIM, So Ra. Da imagem à palavra: medo e ousadia em Hye Seok Rha, Tarsila do Amaral e Frida Kahlo. [Tese doutorado] Porto Alegre: UFRGS, 2005.

MARTINS, Anna Faedrich. Autoficções: do conceito teórico à prática na literatura brasileira contemporânea. [Tese de doutorado] - Porto Alegre: PUCRS, 2014.

MONASTERIO, Pablo Ortiz (organização). Frida Kahlo: suas fotos. São Paulo: Cosac Naify, 2010.

REBEL, Ernst. Autorretratos. Lisboa: Taschen, 2009.

TAYMOR, Julie (dir.). Frida, longa-metragem, 122 min., San Francisco, 2002.

VIANA, Lucia Helena. Tinta e sangue: o diário de Frida Kahlo e os 'quadros' de Clarice Lispector. Revista Estudos Feministas, v. 11, n. 1, edição eletrônica, Florianópolis, jan./jun. 2003.

Bibliografia Pretendida

ALVES, Maria da Penha Casado. Frida Kahlo entre palavras e imagens: A escrita diarista e o acabamento estético. São Paulo: Revista Linha d'água USP, n.2, 2012.

BENSTOCK, Shari (ed.). The Private Self: Theory and Practice of Women's Autobiographical Writings. Chapel Hill: U of North Carolina P, 1988.

GANNIT, Ankori. Imaging Her Selves: Frida Kahlo's Poetics of Identity and Fragmentation. London: Greenwood, 2002.

GONÇALVES, Aguinaldo José. Laokoon revisitado: Relações Homológicas entre Texto e Imagem. São Paulo: Edusp, 1994.

LEJEUNE, Philippe. O pacto autobiográfico. De Rousseau à Internet. [Organização de Jovita Maria G. Noronha. Tradução Jovita Maria G. Noronha e Maria Inês Coimbra Guedes]. Belo Horizonte: Editora UFMG, 2008. 
METAgraphias: letra E (sobre errância e-Rancièrráticas) v.2 n.2 junho| 2017

Frida Kahlo: entre pinturas e escritos • Brígida Duarte (brigidaduart@hotmail.com)

PRAZ, Mario. Literatura e artes visuais (trad. José Paulo Paes). São Paulo: Cultrix/EdUSP, 1982.

SILVEIRA, Paulo. As existências da narrativa no livro de artista [tese doutorado]. Porto Alegre, RS, 2008.

SILVEIRA, Paulo. A Página Violada. Da Ternura à Injúria na Construção do Livro de Artista. $2^{a}$ edição. Porto Alegre: UFRGS, 2008. 